\title{
O sentimento do estrangeiro na esfera intelectiva e afetiva
}

\section{The foreigner's feeling in the inletective and affective sphere}

\section{Robson da Rosa Barcelos ${ }^{1}$}

Universidade Federal de Santa Maria robigolrobson@gmail.com https://orcid.org/0000-0001-5358-5231

\section{RESUMO}

O presente artigo versa sobre o sentimento de estraneidade no ser humano. Em se tratando de ser humano, tradicionalmente se compreende enquanto seres contendo razões e emoções. Dessa forma, para melhor compreensão do sentimento do estrangeiro analisa-se seu contexto sobre a ótica do sentimentalismo moral humeano, e sobre o entrelaçamento, proposto por Husserl, entre as esferas intelectivas e afetivas. A partir desses filósofos percebe-se a convergência entre as esferas intelectiva e afetiva, assim como entre a razão e a emoção. Por conseguinte, teorias emocionais contemporâneas trazem um ganho explicativo para a compreensão do sentimento do estrangeiro diante de novos ambientes e culturas, na medida em que se percebe tanto elementos cognitivos quanto não-cognitivos. Portanto, Goldie e Husserl contribuem para a análise do sentimento de estraneidade do estrangeiro em suas diversas peculiaridades.

Palavras-chave: Razão. Emoção. Sentimento moral. Estraneidade.

\begin{abstract}
This article deals with the feeling of strangeness in the human being. When it comes to being human, it is traditionally understood as beings containing reasons and emotions. Thus, to

${ }^{1}$ Doutorando em Filosofia pela Universidade Federal de Santa Maria. Bolsista da Coordenação de aperfeiçoamento de pessoal de nível superior (CAPES).
\end{abstract}


better understand the feeling of the foreigner, its context is analyzed on the perspective of humean moral sentimentalism and on the intertwining, proposed by Husserl, between the intellectual and affective spheres. From these philosophers one can see the convergence between the intellectual and affective spheres, as well as between reason and emotion. Therefore, contemporary emotional theories bring an explanatory gain for understanding the feeling of the foreigner in the face of new environments and cultures, as both cognitive and non-cognitive elements are perceived. Therefore, Goldie and Husserl contribute to the analysis of the foreigner's feeling of strangeness in its various peculiarities.

Keywords: Reason. Emotion. Moral feeling. Strangeness.

\section{INTRODUÇÃO}

Concebendo o ser humano de forma tradicional, há de um lado a razão e de outro a emoção. Contudo, tal relação, para alguns filósofos, não se demonstra bipolar. Conforme Husserl (2009b), há um entrelaçamento entre as esferas afetivas e intelectiva (FABRI, 2017, p. 93), concepção essa baseada na compreensão da filosofia moral de Hume (1999, 2004, 2009) $)^{2}$. Porém, no nascimento do ser humano, ocorrem alguns fenômenos, tal como ser estranho ao mundo. Arendt (2006) retrata bem esse fenômeno na seguinte passagem,

Quando nascemos no mundo, primeiro nos vemos confrontados exclusivamente com o que aparece, com o perceptível sensivelmente, posto que nascemos nele como estranhos, como recém-chegados desde a perspectiva do mundo, nos sentimos surpreendidos pela admiração, e nossas perguntas conduzem a familiarizar-se com o mundo (ARENDT, 2006, p. 757)

O ser humano, ao nascer, inicia em uma posição de estraneidade perante o mundo. Posto a situação originária do ser, ele se vê admirado, surpreendido, contendo sentimentos inéditos

${ }^{2}$ Cf. HUME, D. An enquiry concerning human understanding. Tom L. Beauchamp (ed.). Oxford: Oxford University Press, 1999; HUME, D. Investigações sobre o entendimento humano e sobre os princípios da moral. Tradução de José O. A. Marques. São Paulo: Unesp, 2004; HUME, D. Tratado da Natureza Humana. Trad. Débora Danowski. 2a edição. São Paulo: UNESP, 2009. 
para si próprio. Dessa forma, para melhor compreensão desse sentimento (se isso for possível) contemporaneamente há teorias dialogando acerca da possibilidade ou não do conhecimento desses sentimentos.

Assim, o presente trabalho tem por objetivo analisar os sentimentos, e emoções da situação originária do ser, a partir de sua posição de estraneidade perante o mundo. Para tanto, se discorre primeiramente acerca da teoria do sentimentalismo moral em Hume, ou seja, dos sentimentos morais, os quais oferecem bases para nossos juízos morais, dos princípios, a saber, da agradabilidade e da utilidade. Posteriormente se versa acerca da esfera intelectiva e da esfera afetiva para Hume e Husserl, pois o segundo propõe uma visão que entrelaça as duas esferas. Por conseguinte, ocorre a explanação da classificação das teorias da emoção na contemporaneidade. Por fim, se intenta a análise dos sentimentos e emoções do estrangeiro sobre a ótica das esferas intelectiva e afetiva.

\section{SENTIMENTALISMO DE DAVID HUME}

Para Hume (1978), pode-se dizer que sua abordagem acerca da moralidade, assim como as justificações das ações humanas são naturalistas. Mas, como conceber um filósofo cético acreditando na natureza humana? Para o filósofo, há características comuns a todos os seres humanos, a saber, os sentimentos. Dessa forma, Hume fornece uma base estável para a moralidade, e para o agir humano. "Para ele, nossas convicções, comprometimentos ou preconceitos são implantados em nossas mentes pela Natureza, e pela vida em sociedade, a qual é uma das imposições da nossa natureza" (CONTE, 2004, p. 168). Percebe-se que tal condição humana não implica em uma determinação cabal do ser humano, mas sim em uma base a partir da qual poderá vir a justificar e valorar o agir humano.

Contudo, ainda persiste uma dúvida, como pode Hume afirmar que a natureza humana dos sentimentos é a base de sua moral, de suas ações?

Em todo sistema de moral que até hoje encontrei, sempre notei que o autor segue durante algum tempo o modo comum de raciocinar, estabelecendo a existência de Deus ou fazendo observações a respeito dos assuntos humanos, quando, de repente, surpreendo-me ao ver que, em vez das cópulas proposicionais usuais, como é e não é, não encontro uma só proposição que não esteja conectada a outra 
por um deve ou não deve. Essa mudança é imperceptível, porém da maior importância. Pois como esse deve ou não deve expressa uma nova relação ou afirmação, esta precisaria ser notada e explicada; ao mesmo tempo, seria preciso que se desse uma razão para algo que parece inteiramente inconcebível, ou seja, como essa nova relação pode ser deduzida de outras inteiramente diferentes (HUME, 1978, p. 469)

Nessa passagem, percebe-se, que o dever deduzido a partir das premissas factuais não é válido para conclusões morais. A alternativa de Hume é que, pelos sentimentos, obtém-se o dever moral. Nesse trecho se aponta a falácia naturalista, a qual na visão de Hume se aplica no âmbito da razão humana. Hume dessa maneira, adverte acerca da incapacidade da razão humana de justificar e motivar a ação humana. Para o filósofo, nós, seres humanos, não possuímos conhecimento total sobre a formação do nosso próprio corpo e, mesmo assim, agimos, utilizando os braços, por exemplo

(...) assim como a natureza nos ensinou o uso de nossos membros sem nos dar conhecimento dos músculos e nervos pelos quais eles são usados, também implantou em nós um instinto que faz avançar o pensamento por linhas de sucessão correspondentes às que estabeleceu entre os objetos, embora desconheçamos os poderes e forças de que dependemos totalmente esse curso e sucessão regular de objetos (HUME, 1999, p. 522)

Dessa maneira, a razão não é capaz de compreender a sucessão dos objetos no mundo, para tanto a natureza humana se encarrega de preencher essa lacuna com algo que acima é referido como instinto.

A razão se demonstra inapta no tocante aos princípios basilares, os quais os demais valores morais são classificados. Dessa maneira, Hume afirma que "Tudo o que tem alguma espécie de valor acomoda-se tão naturalmente à classificação de útil ou agradável - o utile ou o dulce- (...) em relação à própria pessoa ou a outros (...)” (HUME, 2004, p. 347). Diante desse fundamento, para os valores morais, a razão por vezes se dobra a tais princípios basilares, pois isso, em certa medida, explica determinadas ações e sentimentos morais, os quais estão em desconformidade com uma regra, ou norma. Por exemplo, ao querer sempre agir por dever e, em certo momento, defrontar-se com situações que coloquem em risco o “dever”. Isso pode ser aplicado no caso clássico da mentira, no ambiente nazista, ao abrigar um amigo judeu e logo após surge um militar nazista o qual questiona se há um judeu. Nessa 
| Artigos | O sentimento do estrangeiro na esfera intelectiva e afetiva |

| Robson da Rosa Barcelos |

situação devo agir por dever a regra, contudo não me seria agradável entregar meu amigo judeu, logo demonstrando a fraqueza da razão em determinadas situações.

\section{INTELECTO E SENTIMENTO EM HUSSERL E HUME}

Considerando a relação entre intelecto e emoção, em Husserl há uma ligação estreita, mas não oposta. Pois, ao longo da tradição filosófica se considerava a razão enquanto oposta a emoção, mas o desafio era visualizar que há fundamentos teóricos em situações científicas, como situações cotidianas, as quais se firmam em leis e teorias a priori, das quais dependem os juízos lógicos e os juízos éticos (HUSSERL, 2009a, pp. 82-83). Dessa maneira, ocorre uma demonstração da ligação entre a esfera intelectiva e a esfera emotiva, de modo a considerar as leis e teorias a priori enquanto mais originárias, denotando o ponto inicial no agir, no fazer ético.

Do ponto de vista de Husserl, o Eu puro "compreende de maneira evidente" uma verdade fundada, enquanto "como aquilo que é compreendido de maneira evidente" (HUSSERL, 2009b, p. 130). Dessa forma, a compreensão do eu puro demanda um eu empírico, o qual possui uma vida racional, ou seja, percebe, julga, reflete, deseja, compara, entre outros. Isso denota a base da vida racional do ser humano concreto, objetivo no mundo concreto.

Mas permanece um problema, a saber, como fazer passar uma obrigação moral a partir de uma pretensão teórica? Como Husserl afirma, "Cada qual aja segundo a sua consciência" (HUSSERL, 2009b, p. 132). Assim, cada teorização de cada sujeito seria uma forma de obrigação moral. Contudo cabe destacar uma diferença, para Husserl, entre razão judicativa (remete-se a predicados de verdade e falsidade) e razão prática (remete-se a predicados sobre o que é bom e o que é mau a partir do dever). Pode-se questionar em outros termos, a saber: "o que seria uma razão relacionada às motivações da vontade?" (FABRI, 2017, p. 88).

Atribui-se grande força da razão para a motivação da ação. Contudo, isso se denota um problema no racionalismo ético, pois o mesmo relega a compreensão da ética em oposição à razão. Isso ocorre, porque o racionalismo ético deixa de lado a diferenciação 
| Artigos | O sentimento do estrangeiro na esfera intelectiva e afetiva |

| Robson da Rosa Barcelos |

husserliana da razão judicativa e da razão volitiva (HUSSERL, 2009b, p. 133) Dessa forma, se estende a compreensão empirista e naturalista da ética e todos os problemas advindos dessas concepções. No caso do naturalismo, é o problema do fato valor, no qual é possível afirmar que os fatos já contem propriedades morais, por exemplo, ao olhar para uma pessoa negra, dizer que ela é preguiçosa devido a sua genética. Notam-se sérias consequências para o agir humano somente considerando a natureza dos fatos, enquanto portadores de valores morais.

Contudo, para Husserl não há possibilidade de derivar valores morais a partir da natureza. Ele afirma, "A natureza é o reino da incompreensibilidade” (HUSSERL, 2009b, p. 104), a natureza não pode comportar conceitos do mundo espiritual, a saber, motivacional, intencional. Assim, somente a subjetividade humana pode possuir o correlato objeto-valor. Dessa forma, a legislação formal humana, também não pode estar desassociada do empírico. Com isso, Husserl intenta em unir o que foi separado, a saber, o intelecto e o sentimento, no interior da razão prática (FABRI, 2017, pp. 89-90).

A pretensão husserliana pode ser compreendida enquanto, um intelectivismo ou sentimentalismo. No primeiro seria compreender, a partir de um racionalismo, uma validade incondicional e supra-individual, não tendo conexão com o ser humano. Já o sentimentalismo, ou seja, o juízo moral será constituído pelo sentir, pela afetividade humana. Então podemos pensar matematicamente, cientificamente somente na esfera afetiva? Afirmar isso é corroborar a visão naturalista, na qual a partir da consideração dos fatos advém os valores morais, assim na matemática pode-se derivar de uma fórmula um juízo moral. Algo que se demonstra estranho. Logo, Husserl vai de encontro com o pensamento humeano no seguinte ponto, "A união entre motivos e ações 'têm a mesma constância que a união entre quaisquer operações naturais" (HUME, 2009, p. 440, apud, FABRI, 2017, p. 91).

Em Hume, temos uma teoria naturalística do eu. Dessa forma, ele compreende que a razão não pode proporcionar fundamentos acerca da existência do corpo, pois a mente compreende as percepções enquanto feixe de representações, isto é, um feixe de percepções os quais são unidas pela imaginação, que tende a fantasiar a continuidade existencial dos objetos. Já em Husserl, a imaginação constrói as categorias que edificam o eu pessoal. Assim, a crítica ao naturalismo humeano versa acerca da impossibilidade da ciência moral fornecer 
| Artigos | O sentimento do estrangeiro na esfera intelectiva e afetiva $\mid$

| Robson da Rosa Barcelos |

verdades objetivas, já que as categorias objetivas práticas da ciência também são ficções do eu pessoal. Isso se justifica, pois para Hume o entendimento julga por demonstrações (relações abstratas entre ideias) ou probabilidade (relações entre objetos ou experiência), a razão apenas revela a verdade ou falsidade. Entretanto, as paixões (volições e ações) são realidades originais, completas em si mesmas (HUME, 2009, p. 498). Elas não possuem conteúdo proposicional e dessa forma não podem ser avaliadas enquanto verdadeiras ou falsas. As ações são apenas agradáveis ou desagradáveis, úteis a uma ou mais pessoas. "Há duas maneiras pelas quais a razão pode influenciar nossa conduta: a) despertando nossa paixão (informando-nos, por exemplo, sobre um objeto); b) dando meios para se exercer uma paixão" (FABRI, 2017, p. 92)

A razão não é capaz de distinguir entre o bem e o mal. Ela apenas pode encontrar esses deveres e obrigações. Para tanto, há as percepções da mente, a saber, vício e virtude. Assim, o que mais nos importa são os nossos próprios sentimentos de prazer ou desprazer.

Ter o sentimento da virtude é simplesmente sentir uma satisfação de um determinado tipo pela contemplação de um caráter. O próprio sentimento (feeling) constitui nosso elogio ou admiração. Não vamos além disso (HUME, 2009, pp. 510-511).

A moralidade diz respeito aos próprios sentimentos gerados pela experiência do mundo, ou seja, do que afeta. Dessa forma, contemplar uma ação é uma forma de perceber o próprio sentimento e assim, conforme o sujeito, gerar um prazer ou um desprazer e posteriormente uma distinção entre o que seria bem e mal.

Para Husserl, os atos intelectivos são pressupostos dos atos afetivos. Dessa forma, a especificidade do juízo moral não advém somente dos sentimentos de prazer ou desprazer, mas também do entrelaçamento com funções intelectivas para que se possa constituir enquanto objetividades axiológicas. Pois para Husserl, "perceber, representar, julgar, conjecturar, por exemplo, são atos que podem ser pensados sem nenhuma participação em nossos sentimentos, ou seja, são atos sem valorações, atos puramente intelectivos" (HUSSERL, 2009a, p. 334 apud FABRI, 2017, p. 93). Mas, como os atos intelectivos se fundem com atos afetivos? Para Husserl na esfera afetiva (da razão prática), um simples ato afetivo em geral não objetifica algo no mundo, tanto quanto se separa do entendimento. 
Contudo para Hume, a razão diz respeito à conclusão, à demonstração, à comparação, à refutação, e diante do sentimento, isso se torna vazio. Dessa maneira ela sozinha não gera a ação, pois "Nada pode se opor ao impulso da paixão, ou retardá-lo, senão um impulso contrário" (HUME, 2009, p. 450).

Porém, ainda persiste a dúvida, como o ato intelectivo se relaciona com o ato afetivo, visto que sentimento não é um ato intelectivo. "Hume permite considerar a intencionalidade do sentimento a partir dela mesma, sem que para tal ela seja medida por um conhecimento objetivo" (FABRI, 2017, p. 95), a partir do entrelaçamento das percepções, por meio de associações, surgem novas intencionalidades, e conforme Husserl, a associação se compreende enquanto causalidade motivacional. Assim, a esfera afetiva é parte da vida intencional na sua totalidade e posta ao lado da racionalidade prática se aproxima do intelecto.

Em todo o sentir encontra-se um valorar [...]. Este pode ser um valorar correto ou incorreto, um valorar que se adapta ou não se adapta ao objeto, ou ainda: pode ser um valorar que põe um valor falso ou verdadeiro (HUSSERL, 2009b, p. 177).

Dessa maneira, a verdade cognoscitiva habita o âmbito do sentimento e da vontade. "Ou seja, a razão prática e valorativa existe antes do pensamento numa espécie de objetivação préteórica" (HUSSERL, 2009b, p.181 apud FABRI, 2017, p. 95)

Contudo Hume entende o eu, enquanto um feixe de percepções, no qual uma associação une todos em uma espécie de ficção. Consequentemente, as causas motivacionais do agir também são consideradas ficções, constituindo a identidade do eu. Entretanto, para Husserl o eu é um centro de afecções e ações, contendo forma de "poder", o qual pode fazer, agir, pensar, etc. Assim, os atos do eu não são meramente empíricos. Pois, os racionalistas deixam isso escapar aquilo que Hume demonstra de modo singular, a saber, "a infinita variedade das formações de consciência” (HUSSERL, 2009b, p. 193).

No tópico seguinte, prosseguiremos com a análise da relação entre os sentimentos e a razão, na qual uma peculiar característica do ser humano, a saber, a relação do eu com os demais seres humanos, irrompe sentimentos de estraneidade, ou seja, sentimento do estrangeiro. 


\section{VIVÊNCIA E EXPERIÊNCIA DO ESTRANHO (ESTRANGEIRO)}

Notoriamente em viagem a outros locais, se vislumbra o novo panorama que se vivencia. Na terra natal o ambiente não é estranho e não se percebe da mesma forma que os novos lugares, pois as pessoas são consideradas parte do ambiente com seu modo peculiar de ser, de agir e de falar. Os hábitos já são naturais, comuns, os quais são reconhecidos como sendo próprios da cidade natal. Dessa maneira, a ação ocorre, por vezes, de tal forma sem ser percebida como é, como de fato ela reflete a cultura local. Tanto quanto, não se nota as demais pessoas, no sentido de perceber o outro como uma pessoa diferente da comunidade. Logo, as pessoas do entorno são familiares.

O sujeito ao adentrar em um novo mundo, ou seja, ao tirar férias em outra cidade desenvolve sentimento de estraneidade em um novo entorno. Em outras palavras, ao ir visitar uma cidade nova, com pessoas diferentes, de culturas distintas, o sujeito se sente em um ambiente estranho ao dele próprio. Dessa forma, o sujeito de férias se torna estrangeiro em terras distantes da sua cidade natal. Ou seja, "Ele torna-se essencialmente o homem que tem que colocar em questão, aproximadamente, quase tudo que parece ser inquestionável para os membros do grupo ao qual ele se aproxima" (SCHÜTZ, 2010, p. 6). Assim, o estrangeiro é aquele que questionará toda cultura dos cidadãos da pólis, ou seja, utilizando atos intelectivos. Isso não se deve a uma mera prepotência de classificar a sua cultura como melhor do que a vivenciada, mas sim para identificar "O padrão cultural do grupo aproximado, então, não é mais um assunto subjetivo de seu pensamento, mas um segmento do mundo que tem que ser dominado por ações" (SCHÜTZ, 2010, p. 7).

As ações do estrangeiro no entorno que lhe é característico, ou seja, aquele no qual ele se encontra deslocado, estranho, se guia pela cultura local. Contudo, há coisas das quais o sujeito somente vivencia. Para tanto, o estrangeiro passa a vivenciar e conhecer a cultura local, no qual ele se encontra em "um campo de aventuras, não uma coisa natural, mas um questionável tópico de investigação, não um instrumento para desvendar situações problemáticas, e sim ele mesmo uma situação problemática e difícil para dominar" (SCHÜTZ, 2010, p. 12). E eis o ponto importante, pois é o próprio estrangeiro em situação 
de desconforto, emergindo emoções ${ }^{3}$ comuns a todo estrangeiro, a saber, oscilando "entre afastamento e intimidade, sua hesitação e incerteza, e sua desconfiança (...)" (SCHÜTZ, 2010, pp. 11-12). Percebe-se nesse ponto que, imerso em uma cultura estranha ao estrangeiro, ele aciona seus atos intelectivos, assim como seus atos afetivos, a saber suas emoções perante seu entorno. $\mathrm{O}$ ambiente de estraneidade vem corroborar a conceituação de Damásio acerca da sequência de nossas próprias emoções para sentimentos, pois inicialmente nos encontramos em uma posição de estraneidade perante o nosso entorno para posteriormente interiorizarmos as emoções e, em certa medida, clarificá-la em nossa mente, isto é, justificando, compreendendo, analisando o ocorrido conosco nessa difícil aventura.

A vivência do estranho no âmbito alheio a si mesmo gera emoções familiares a outros âmbitos, aos quais ele esteve concretamente. Dessa forma, se percebe o papel crucial da experiência concreta do corpo, pois a tradição explica que a subjetividade do estranho estaria calcada numa interioridade, numa profundidade por vezes inacessível à razão. Assim, Nietzsche considera que "O corpo, a partir daí, não é identificado qual um invólucro que envolve a essência do eu, mas sim que ele faz 'eu'. Nesse sentido, nós não mais somos possuidores de um corpo, nós somos um corpo" (FARIAS, 2013, p. 106). Portanto, considerando a capacidade do corpo gerar em nós emoções, conforme Damásio, e já o contemporâneo filósofo, Nietzsche, versa acerca de um si-mesmo, que não habita meu corpo, mas é meu corpo, do qual se toma como ponto de partida para o entendimento. Portanto, a estraneidade é corporificada e dessa maneira passível de compreensão.

O estrangeiro se depara com uma cultura diferente da sua, a qual impele-o a responder e tal resposta contém tanto esferas afetivas, quanto intelectivas. A medida em que o estrangeiro imerge na cultura alheia causa estranheza para si e os demais. Assim, se coloca num lugar de responsividade. Ou seja, o sujeito vê-se impelido a agir, a dar uma resposta ao

\footnotetext{
3 “A emoção e as várias reações com ela relacionadas estão alinhadas com o corpo, enquanto os sentimentos estão alinhados com a mente" (DAMÁSIO, 2004, p. 15). "Mas na tentativa de compreender a cadeia complexa dos acontecimentos que começa na emoção e termina no sentimento, separar a parte do processo que se torna pública da que sempre se mantém privada ajuda a clarificar as ideias. À parte pública do processo como emoção e à parte privada sentimentos (...)" (DAMÁSIO, 2004, pp. 34-35).
} 
| Artigos | O sentimento do estrangeiro na esfera intelectiva e afetiva |

| Robson da Rosa Barcelos |

estranho. Tal resposta pode ser a mais diversa possível, contudo, segundo Waldenfels (1997) pode ser repetitiva ou reprodutiva e inovadora ou produtiva.

El responder camina, por conseguinte, sobre un estrecho filo, que separa la mera servidumbre y la condescendencia, del capricho y de la arbitrariedad. Quien aguarda respuestas acabada tiene nada que decir, porque todo está ya dicho. Quien, a la inversa, habla sin responder, tampoco tiene nada que decir, puesto que para él no hay nada que decir. Inventamos lo que respondemos, pero no aquello a lo que respondemos y que le da peso a nuestro hablar y actuar (WALDENFELS, 1997, p. 26).

Se repetir a resposta perante o estranho, o estrangeiro não necessita dizer nada, pois tudo já foi dito. Se reproduzir a resposta, é o mesmo que falar sem responder nada e da mesma maneira, não há nada para ser dito. Porém, ao se inventar a resposta, ganha valor, tanto para a fala, quanto para a ação. Neste último ponto pode-se dizer que passa a utilizar a esfera afetiva, assim como a esfera intelectiva. Essa resposta do estrangeiro pode ter uma carga de violência perante o estranho, por exemplo, uma pessoa que sai do interior para uma capital, e ao ser assaltada reage com a mesma proporção de violência. Dessa maneira, essa resposta do estrangeiro perante o estranho, se demonstra para os cidadãos da pólis diferente, inovadora no sentido de não ser habitual. Para tanto, o sujeito da resposta engendra tanto a esfera afetiva, ao responder ao ambiente, quanto na esfera intelectiva, ao utilizar suas percepções para compreender o que ocorria consigo mesmo.

O sujeito imerso na estraneidade, se encontra na posição de estrangeiro, ou seja, está exposto. Esta ultra-exposição, impele o estrangeiro a responder ao novo que surge diante dele. O estrangeiro é obrigado a responder. A percepção do estrangeiro, da qual se vale para sua resposta, não nasce de uma ação intencional. As percepções do estrangeiro surgem como um prestar atenção para aquilo que o fere e o golpeia, isto é, choca a sua sensibilidade. Com isso, há uma passagem do âmbito fenomenológico implicando no âmbito ético, pois na medida em que se responde a relação assimétrica entre o estrangeiro e o cidadão da pólis, ocorre uma responsabilidade pela resposta, que como anteriormente mencionado por Waldenfels (1997) demonstra a relação por mero capricho ou por arbitrariedade. No conto "Funes, o memorioso" de Jorge Luis Borges é especulada a imagem de alguém que nada consegue esquecer. Irineu Funes, o protagonista da história, sofreu um acidente que lhe fez 
perder a capacidade de esquecer. Funes é apelidado como "o memorioso", pois devido a sua incapacidade de esquecer, vira uma doença, ou seja, nada lhe escapava. "- minha memória, senhor, é como um despejadouro de lixos" (BORGES, 2005, p. 543). No contraponto ao estrangeiro, o qual está a adquirir conhecimento, ou a se tornar cidadão da pólis, o Funes seria classificado enquanto cidadão global, ou melhor, cidadão do mundo, pois ao entrar em contato com o estranho já modifica seu lugar. Depois do choque com o estranho, em seguida ele se lembra de tudo, adquirindo assim sua cidadania por meio de sua memória, a qual é sua chave mestra para as diferentes realidades vivenciadas e assimiladas pela sua incessante e gulosa memória.Para melhor compreensão do sentimento de estraneidade do sujeito, a seguir, discorre-se brevemente sobre teorias emocionais contemporâneas. Essas teorias trazem informações importantes para a análise dos elementos do ser estrangeiro em sociedades e culturas que não lhe são próprias.

\section{TEORIAS DAS EMOÇÕES}

Em nossa vida mental um dos aspectos mais importantes que a qualificam e significam é as emoções. Contudo, qual a ontologia das emoções? Conforme De Sousa (2014), as emoções "Podem ser processos físiológicos, ou percepções de processos fisiológicos, ou estados neuropsicológicos, ou disposições adaptativas, julgamentos avaliativos ou estados computacionais, ou mesmo fatos sociais ou processos dinâmicos"4 (DE SOUSA, 2014, p. 10).

Dessa forma, na tradição filosófica há diversas teorias sobre as emoções. A saber, estas são as teorias cognitivas, não-cognitivistas e narrativas. As teorias cognitivas caracterizam as emoções como cognições associadas, isto é, ocorrem processos cognitivos subjacentes à emoção, podendo ser conscientes ou não, mas que possuem atitude proposicional. Já a teoria não-cognitivista se caracteriza por ser subjetiva, ou seja, com a direção de ajuste mente-mundo. E as teorias narrativas, as quais visam ajustar as teorias

4 "They might be physiological processes, or perceptions of physiological processes, or neuropsychological states, or adaptive dispositions, or evaluative judgments, or computational states, or even social facts or dynamical processes" (DE SOUSA, 2014, p. 10). 
| Artigos | O sentimento do estrangeiro na esfera intelectiva e afetiva |

| Robson da Rosa Barcelos |

cognitivas e não-cognitivas, na medida em que considera o poder de direção das emoções sobre nossas percepções, já está baseada em estruturas essencialmente dramáticas ou narrativas (Cf. DE SOUSA, 2014). Por exemplo, a emoção de ciúmes ou de raiva não se constituiria no momento presente, sem que houvesse uma base cognitiva, ou seja, um histórico de ações que me levem a ter ciúmes.

\subsection{Emoções: juízos de valor, processos afetivos e teoria narrativa}

Passemos agora para o esclarecimento, rápido e simples para a presente proposta. Dessa maneira, percebe-se alguns problemas para a atribuição de um estado mental do tipo emoção. Conforme as teorias cognitivas, as emoções possuem a característica de serem atitudes proposicionais, assim o juízo de valor pode, segundo Robert Solomon (1980), Jerome Neu (1980) e Martha Nussbaum (2001), por exemplo, ao ter raiva de alguém ser o meu julgamento sobre aquela pessoa. Assim a emoções podem ser descritas como "conjuntos de crenças e desejos (MARKS, 1982), julgamentos afetados (BROAD, 1971; LYONS, 1980) e como complexos de crenças, desejos e sentimentos (OAKLEY, 1992)" ${ }^{\prime 5}$ (DE SOUSA, 2013, p. 7). Tal concepção exclui animais e crianças carentes de linguagem de terem emoções. Ainda Nussbaum (2001, p. 29) compreende emoções como juízos de valor, ou seja, assume, ou adota uma forma de perceber o mundo, reconhecer tal percepção como verdadeira, o qual requer o poder discriminativo da cognição. As emoções podem ser compreendidas como juízos, então esses estados mentais possuem eventos cognitivos. Isso se denota como uma direção a um objeto, a qual possui um valor desse objeto em relação ao agente da percepção.

Já segundo as teorias não-cognitivistas das emoções, a inquietação versa sobre a suposta subjetividade, ou seja, enquanto processos afetivos. Logo, ao que parece, a subjetividade é referente à experiência que o sujeito traz em sua mente. Assim, afirmar que as emoções são subjetivas é, em certa medida, possibilitar a comparação com alucinações,

5 "Emotions have been described as sets of beliefs and desires (Marks 1982), affect-laden judgments (Broad 1971; Lyons 1980), and as complexes of beliefs, desires, and feelings (Oakley 1992)” (DE SOUSA, 2013, p. 7) 
| Artigos | O sentimento do estrangeiro na esfera intelectiva e afetiva |

| Robson da Rosa Barcelos |

mais do que as próprias percepções, sendo que para se obter as experiências pressupõe-se que haja um objeto. Porém, Robinson (2005, p. 157) baseada em experiências psicológicas, identifica as emoções com processos afetivos pré-cognitivos não proposicionais desencadeados por algum elemento do ambiente que sensibiliza os indivíduos, o qual proporciona modificações fisiológicas no indivíduo, expressões físicas e tendência à ação. Outra dificuldade reside na sua passividade, ou seja, como o mundo é não está em nosso poder. Dessa maneira, somente podemos esperar que nossas emoções, se possuem alguma objetividade no mundo, não deveriam estar em nosso poder. Portanto, “(...) não podemos mais arbitrariamente escolher experimentar uma emoção do que podemos adotar uma crença à vontade (GORDON, 1987)" (DE SOUSA, 2014, p. 9).

Conectando ambas as posições, cognitivistas e não-cognitivistas, a teoria narrativa intenta realizar uma união, ou, ao menos, um tratado de paz, pois considera a emoção complexa, episódica, dinâmica e estruturada narrativamente (GOLDIE, 2000, p. 12-13). Por exemplo, imaginem o cenário de trabalho comum, no qual, durante seis dias por semana, adentra-se numa sala e o funcionário se isola do mundo. Ele até chega a ligar para sua casa, onde sua esposa trabalha, executando suas tarefas. Entretanto, por diversas vezes, ele liga e ouve vozes de outras pessoas na sua casa, e ao retornar ao seu lar, a sua esposa sempre está dormindo, não havendo relações afetivas entre o casal. Com isso ele passa a ficar com ciúmes das vozes, e de qualquer companhia que a esposa possa ter durante a sua ausência. Nesse exemplo, a partir das percepções do próprio sujeito se constitui a crença de que ele poderia estar sendo traído. Em vistas disso, ele tem ciúmes e, conforme sua experiência, aquela situação denotaria uma traição por parte de sua esposa. Assim, a emoção de ciúmes não surge em segundos, mas sim na própria percepção, na construção da crença e na formulação da emoção.

Para melhor compreender a possível relação entre Husserl e contemporâneos da teoria da emoção realiza-se uma breve comparação. No viés cognitivo exposto por Nussbaum, considerando as emoções enquanto eventos cognitivos, ou seja, como juízos de valor, podese dizer que estão próximas da esfera intelectiva de Husserl, pois processos de julgamentos,

6 “(...) we can no more arbitrarily choose to experience an emotion than we can adopt a belief at will. (GORDON, 1987)” (DE SOUSA, 2014, p. 9) 
comparação, conjecturas, reflexões também são eventos cognitivos e estão presentes nos juízos. Com isso, ao considerar-se as emoções como processos cognitivos, também pode-se enquadrá-las na esfera intelectiva, constatando que as emoções podem entrelaçar-se com a razão, mesmo em teorias contemporâneas. Ao passo que, a esfera afetiva de Husserl, dos sentimentos, são consoantes com as emoções enquanto não-cognitivas de Robinson. Pois, esses processos afetivos se caracterizam enquanto pré-cognitivos desencadeados por estímulos no ambiente. Dessa forma não parece haver problemas nessa afirmação, de que processos não-cognitivos podem se enquadrar na esfera afetiva. Logo, Goldie com a estrutura narrativa sobre as emoções realiza a união entre as posições contemporâneas, os cognitivos e não-cognitivos, assim como Husserl realiza o entrelaçamento da esfera intelectiva e esfera afetiva. Ambos levam em consideração algo a mais para essa aproximação, Goldie caracteriza as emoções como complexas, dinâmicas, episódicas e com estrutura narrativa. Já Husserl aproxima a esfera afetiva da intelectiva no âmbito da racionalidade prática, pois somente o entendimento, a saber, demonstração, refutação, comparação, julgamento, entre outros isolados, se tornam vazios. Assim os dois filósofos entrelaçam as aparentes oposições.

\section{CONCLUSÃO}

A razão humana enquanto fundamento último para agir humano, para Hume, se demonstra falha. Ou seja, se as regras são seguidas à risca, então o ser humano viveria de acordo com as normas, sem haver problemas de convivência. Porém, as pessoas nem sempre seguem as regras, mas por quê? Para o filósofo as pessoas são movidas pelas paixões, as quais advém dos dois principais princípios fundantes dos sentimentos morais, a saber, da agradabilidade e utilidade. A partir deles forma-se os juízos morais e motivação para a ação.

Contudo, Hume divide o ser humano em razão e emoção, e os coloca enquanto opostos. Husserl diverge dessa posição, e estabelece uma perspectiva de entrelaçamento. Tal entrelaçar a esfera afetiva e a esfera intelectiva se denota profícuo. Isso se deve a racionalidade prática, na qual a vida intencional, proporcionada pelo sentimento enquanto sentimento, isto é, considerar o sentimento sem a necessidade do conhecimento objetificado do mundo. Dessa forma, a cada nova associação que o estrangeiro, mesmo que ficticiamente 
constitui, permite uma nova intencionalidade, a qual aproximada da racionalidade prática, acerca-se da esfera intelectiva, compreendida enquanto perceber, representar, julgar, conjecturar, entre outros. Isso denota o entrelaçamento entre as esferas afetiva e intelectiva.

Também se percebe que nas teorias sobre as emoções temos três posições. A primeira considera as emoções, como juízos de valor, assim se enquadram como eventos cognitivos (NUSSBAUM, 2001). Já as emoções no âmbito do não-cognitivo considera-as como processo afetivos, desencadeados por estímulos do ambiente, dessa forma se considera como pré-cognitivos (ROBINSON, 2005). Já Goldie (2012) versa sobre as emoções como complexas dinâmicas, episódicas e com estruturas narrativas. Colocando tais teorias em comparação com as esferas intelectivas e afetivas de Husserl ganha-se uma melhor compreensão acerca das emoções e sentimentos das pessoas, assim como do estrangeiro.

Portanto, perceber o sentimento do estrangeiro como um único processo, ou em uma única esfera, delimita a compreensão da experiência de estraneidade. Sendo que, o sentimento de estraneidade contém tantos elementos cognitivos como não-cognitivos, por exemplo, os juízos morais formulados, o são após o estímulo do ambiente, da cultura, entre outros. Dessa forma, é possível enquadrar o sentimento de estraneidade em Goldie, pois o estrangeiro se defronta com algo complexo, que aos poucos ele utiliza tanto as esferas intelectiva quanto afetiva (não somente uma) para compreender sua posição e tomar a melhor atitude para constituir sentimentos agradáveis para si e para os demais. Assim, Goldie e Husserl auxiliam na compreensão do sentimento do estrangeiro, na medida em que se considera as duas esferas, tanto quanto, caracterizado como complexo (possui diversos elementos), dinâmico (a intensidade da vivência ora aumenta ora diminui), episódica (pois, o estrangeiro pode considerar um único contexto) e estruturas narrativas (assim o estrangeiro pode dividir suas experiências da melhor forma que lhe aprouver).

\section{Referências bibliográficas}

ARENDT, H. Entre o passado e o futuro. Tradução de Mauro W. Barbosa. 5. ed. São Paulo: Perspectiva, 2003. 
| Artigos | O sentimento do estrangeiro na esfera intelectiva e afetiva |

| Robson da Rosa Barcelos |

BORGES, J. L. Funes, o memorioso. In: Obras Completas I. Trad. Flávio José Cardozo. São Paulo: Editora Globo, 2005.

BROAD, C. D. Five Types of Ethical Theory. Londres: Kegan Paul, 1948.

CONTE, J. 2009. A natureza moral de Hume. São Paulo. 208 f. Tese de Doutorado em Filosofia. Universidade de São Paulo.

DAMÁSIO, A. Em busca de Espinosa: prazer e dor na ciência dos sentimentos. São Paulo: Companhia das Letras, 2004.

DE SOUSA, R. (2014) Emotion. In: The Stanford Encyclopedia of Philosophy. ZALTA, E.N. (ed.). Disponível em: <https://plato.stanford.edu/archives/spr2014/entries/emotion/>. Acesso em: 10 mai. 2017.

FABRI, M. Subjetividade e afetividade: o entrelaçamento de intelecto e sentimento na ética de Edmund Husserl. In.: Aoristo: International Journal of Phenomenology, Hermeneutics and Metaphysics, Toledo, v. 2, n. 1, p. 85-97, 2017.

FARIAS, Í. S. Nietzsche: da recusa do "eu" à criação de si mesmo. In.: Revista Lampejo, v. 1, n. 3, pp. 102-109, 2013.

GOLDIE, P. The mess inside. Narrrative, Emotion, \& the Mind. Oxford: Oxford University Press, 2012.

. Emotions as Judgments of Value and Importance. In.: SOLOMON, R. C. (org.). Thinking about Feeling: Contemporary Philosophers On Emotions. Oxford: Oxford University Press, 2004.

- The Emotions: A Philosophical Exploration. New York: Oxford UniversityPress, 2000.

GORDON, Robert. The Structure of Emotions, Cambridge: Cambridge University Press, 1987.

HUME, D. An enquiry concerning human understanding. Tom L. Beauchamp (ed.). Oxford: Oxford University Press, 1999. 
| Artigos | O sentimento do estrangeiro na esfera intelectiva e afetiva |

| Robson da Rosa Barcelos |

. (1739-40). A Treatise of Human Nature, 2nd edn. SELBY-BIGGE, L. A.; NIDDITCH, P.H. (eds.). Oxford: Clarendon Press, 1978.

. Investigações sobre o entendimento humano e sobre os princípios da moral. Tradução de José O. A. Marques. São Paulo: Unesp, 2004.

. Tratado da Natureza Humana. Trad. Débora Danowski. 2a edição. São Paulo: UNESP, 2009.

HUSSERL, E. Leçons sur l'éthique et la téorie de la valeur (1908-1914). Trad. P. Ducat, P. Lang et C. Lobo, Paris: PUF, 2009a. . Introduzione all'etica. Trad. Nicola Zippel, Roma-Bari: Laterza, 2009b.

JAMES, W. The Principles of Psychology. Harvard: University Press, 1890/1983.

. What is emotion? Oxford: Oxford Journal,1884. Disponível em: $<$ http://mind.oxfordjournals.org>. Acesso em: 19 dez. 2016.

LYONS, William. Emotion, Cambridge: Cambridge University Press, 1980.

MARKS, Joel. A Theory of Emotion, Philosophical Studies, Vol. 42, nº 2, pp. 227-242, 1982. Disponível em:< https://www.jstor.org/stable/4319554>

NEU, J. Jealous Thoughts. In: RORTY, A. (Ed.). Explaining Emotions. Berkeley: University of California Press, 1980.

NUSSBAUM, M. C. Upheavals of Thought: The Intelligence of Emotions. Cambridge: Cambridge University Press, 2001.

OAKLEY, Justin. Morality and the Emotions, London: Routledge and Kegan Paul, 1992.

PRINZ, J. The moral emotions. In: GOLDIE, P. (ed.). The Oxford Handbook of Philosophy of Emotion. Oxford: Oxford University Press, 2010.

ROBINSON, J. Deeper than Reason: Emotion and its Role on Literature, Music and Art. New York: Oxford University Press, 2005. 
| Artigos | O sentimento do estrangeiro na esfera intelectiva e afetiva |

| Robson da Rosa Barcelos |

. Emotion: Biological Fact or Social Construction? In: SOLOMON, R. C. (ed.).

Thinking about Feeling: Contemporary Philosophers on Emotions. Oxford: Oxford University Press, 2004, pp. 28-43.

SCHÜTZ, A. O estrangeiro: um ensaio em psicologia social. Tradução de Márcio Duarte e Michael Hanke. Revista Espaço Acadêmico, nº 113, p.117-129, out. 2010.

ZIMMERMAN, A. Moral epistemology. New York: Routledge, 2010.

WALDENFELS, B. Respuesta a lo extraño: rasgos fundamentais de una fenomenologia responsiva. Daimon Revista Internacional de Filosofía, n. 14, p. 17-26, 1997. Disponível em: $<\mathrm{http} / /$ revistas.um.es/daimon/article/view/9111>

Recebido em: 05/08/2019 | Aprovado em: 29/12/2020 